\title{
Causes, diagnosis and treatment of occupational asthma
}

\section{Rahmathulla Safiyul Rahman ${ }^{1 *}$, Hussain Radhi Al Ebrahim ${ }^{2}$, Jarallah Hadi Alqahtani ${ }^{3}$, Danah Jazaa Alomani ${ }^{2}$, Atheer Yusof Al-lihaibi ${ }^{2}$, Mubarak Mohamed Althaidy ${ }^{2}$, Mansour Saad Mohammed ${ }^{4}$, Haneen Sameer Aldosari², Reem Emad Alsayed ${ }^{2}$, Marah Rashed Aljassar ${ }^{2}$, Farah Rashed Aljassar ${ }^{5}$}

\author{
${ }^{1}$ Department of Internal Medicine, Sameera Medical Center, Jeddah, Saudi Arabia \\ ${ }^{2}$ College of Medicine, Arabian Gulf University, Manama, Bahrain \\ ${ }^{3}$ Department of Internal Medicine, Aseer Central Hospital, Abha, Saudi Arabia \\ ${ }^{4}$ College of Medicine, King Khalid University, Abha, Saudi Arabia \\ ${ }^{5}$ Department of Internal Medicine, Farwaniya Hospital, Kuwait City, Kuwait
}

Received: 29 September 2021

Revised: 05 October 2021

Accepted: 14 October 2021

\author{
*Correspondence: \\ Dr. Rahmathulla Safiyul Rahman, \\ E-mail: safiyul@gmail.com
}

Copyright: (c) the author(s), publisher and licensee Medip Academy. This is an open-access article distributed under the terms of the Creative Commons Attribution Non-Commercial License, which permits unrestricted non-commercial use, distribution, and reproduction in any medium, provided the original work is properly cited.

\begin{abstract}
Occupational asthma is usually characterized by airway hyperresponsiveness, airway obstruction, and airway inflammation that usually result from exposure to specific irritants in the workplace and is not usually associated with any evidence of exacerbation outside the workplace. Occupational asthma can be associated with complicated longterm outcomes because affected patients are not usually aware of the hazards of the condition. Therefore, applying adequate diagnostic and management approaches is essential to enhance the outcomes among high-risk workers. In the present literature review, we have discussed the causes, diagnosis, and management of occupational asthma based on the evidence obtained from the current studies in the literature. Our findings indicated the presence of various environmental triggers that can lead to the development of asthma in the workplace, including HMW and LMW compounds. The diagnosis of asthma is based on obtaining a thorough personal and clinical history from the affected patient. However, such approaches have been reported to have low specificity rates, and therefore, the diagnosis should be established by other measures as lung function tests. The management of asthma is hugely dependent on the clinical phenotypes of occupational asthma. Nevertheless, applying adequate interventions can significantly enhance the outcomes in the affected patients, in addition to the other measures that have been adequately discussed in the manuscript.
\end{abstract}

Keywords: Occupational asthma, Etiology, Diagnosis, Treatment

\section{INTRODUCTION}

Worldwide estimates show that asthma affects around 360 million patients, and it has been demonstrated that workrelated asthma represents around a quarter of all of the reported adult-onset asthma. ${ }^{1,2}$ Work-related asthma is a term used to describe a certain type of asthma that is associated with the workplace of the affected patients and includes work-exacerbated asthma, and occupational asthma.

Occupational asthma is usually characterized by airway hyperresponsiveness, airway obstruction, and airway inflammation that usually result from exposure to specific irritants in the workplace and is not usually associated with any evidence of exacerbation outside the workplace. ${ }^{3-5}$ There are two main clinical phenotypes of asthma that 
were reported among the different studies in the literature, including (1) occupational asthma due to exposure to workplace sensitizers and can be immunological or allergic; and (2) occupational asthma due to exposure to irritants at the workplace and is not immunological or allergic but can induce a significant airway reaction that usually leads to the development of reactive airways dysfunction syndrome. Occupational asthma can be associated with complicated long-term outcomes because affected patients are not usually aware of the hazards of the condition. Therefore, applying adequate diagnostic and management approaches is essential to enhance the outcomes among high-risk workers.

The aim of the study was to discuss the causes, diagnosis, and management of occupational asthma.

\section{METHODS}

This literature review was based on an extensive literature search in Medline, Cochrane, and Embase databases which was performed on $3^{\text {rd }}$ September 2021 using the medical subject headings (MeSH) or a combination of all possible related terms. This was followed by the manual search for papers in Google Scholar while the reference lists of the initially included papers. Papers discussing the occupational asthma were screened for relevant information, with no limitation placed on date, language, age of participants, or publication type.

\section{DISCUSSION}

\section{Causes}

Many causative agents can attribute to the development of occupational asthma that has been priorly discussed in the literature, including various airborne agents. ${ }^{4,6}$ Estimates show that occupational asthma can occur secondary to the exposure of more than 350 agents. ${ }^{2,7}$ Besides, further agents are also being identified each year. The causative agents might be high or low-molecular-weight agents (HMW and LMW). Diisocyanates (an LMW compound that is widely available in glues, various paints, and insulations) and flour (an HMW agent) have been reported to be the most common agents to induce occupational asthma, with an estimated rate of $20 \%$ in the developed countries. $^{8,9}$

Fumes, irritant gases, aerosols, and smoke can also lead to the development of occupational asthma. It is well known that HMW agents are usually derived from a plant origin and are composed of polysaccharides and proteins that have a significant ability to induce IgE-related occupational asthma as a result of their complete sensitizing impact. $^{2}$ Therefore, the pathology of occupational asthma requires frequent and prolonged exposure to these substances to finally lead to mast cell activation that can significantly trigger the pathology of the condition. Different occupations are being daily exposed to certain HMW compounds that can efficiently induce occupational asthma. For instance, farm and laboratory animal workers can develop asthma secondary to the frequent exposure of mammalian proteins that are usually present in the fur, saliva, dander, and urine. ${ }^{6,10}$ Accordingly, it has been demonstrated that having a history of sensitization to animals should be considered a risk factor for developing occupational asthma, although it has been previously demonstrated that general atopy is not usually adequately predictive.

Insects can also have a potential role in developing occupational asthma as they can transfer allergens as indicated with the exposure of bait workers to mealworm larva exoskeleton dust. ${ }^{11,12}$ Fish and shellfish, cereals and flours, and exposure to natural rubber latex are also important factors that can contribute to the development of occupational asthma. ${ }^{6}$ Natural rubber latex was reported to commonly cause occupational asthma. However, the prevalence of the condition has been significantly reduced as a result of the reduced utilization of latex-powdered gloves. Enzymes are also reported as causative agents and are usually found in multiple occupations as baking, pharmacological preparations, and detergent manufacture. ${ }^{6,8,13}$ Many LMW compounds were also reported in the literature to cause occupational asthma, including trimellitic anhydride, diisocyanates, and formaldehyde. These compounds lead to the development of occupational asthma by non-immunological mechanisms. Wood dust can also lead to the development of occupational asthma. Exposure to acrylates and persulfate salts were also reported to cause the condition among dentists and hairdressers, respectively. ${ }^{6,14-17}$ Metalloids and metals have also been reportedly associated with occupational asthma. However, the mechanism of such events is poorly understood. The development of occupational asthma can be secondary to exposure to a single compound. Furthermore, it has been demonstrated that certain occupations can expose workers to multiple HMW and LMW substances.

\section{Diagnosis}

Early diagnosis of occupational asthma is necessary to enhance the health-related outcomes of the affected patients. The best diagnostic approach can be obtained by a combination of obtaining an adequate clinical and personal history from the patient, and performing indicative diagnostic tests to establish a proper diagnosis. Peak expiratory flow (PEF) can be performed to discover whether any airway changes can be related to the work, sputum eosinophilic counts, non-specific BHR, evidence for Specific sensitization (SPT) and/or FeNO, SIC, sIgE, and Basaltic activation test (BAT). ${ }^{18}$ Moreover, it is also recommended that an adequate differential diagnosis should be considered and conditions that might result secondary to the exposure of irritants should be excluded and might include hyperventilation syndrome, vocal cord dysfunction, and mass psychogenic conditions. ${ }^{19,20}$ Obtaining a personal history from the patient can be simply guided by asking the patient about the timing of symptoms 
worsening, which is usually during the time of work while outside the workplace; symptoms usually relieve. However, it should be noted that asthma symptoms can also be present outside the workplace as a result of the potential exposure to other irritants as smoke, fumes, and performing exercises that might trigger asthma symptoms. ${ }^{19}$

The diagnosis of occupational asthma is usually delayed to 2-3 years following the appearance of symptoms because workers are not usually aware of the condition because potential symptoms remission within the weekends and in the evening tend to fade away when these workers have continuously been exposed to the causative agents. ${ }^{20}$ Occupation, respiratory symptoms, the presence of dermatitis or urticaria, and other respiratory conditions as conjunctivitis and/or rhinitis. ${ }^{19,20}$ However, it should be noted that obtaining a personal and clinical history is not always adequate to establish a proper diagnosis, and therefore, the diagnosis should be indicated using lung function tests. ${ }^{19,21,22}$

The presence of asthma can be adequately diagnosed by reversible airflow obstruction. ${ }^{20,23}$ However, the diagnosis should be conducted when the patient is still employed to conduct a proper comparison of the respiratory functions outside the workplace and while working. However, it was also reported that lung functions tests are not very specific in diagnosing asthma. ${ }^{24-26}$ Assessment of the non-specific BHR is considered a mandatory test for patients that suffer from non-irritant conditions. Challenges of histamine and methacholine inhalation have been previously reported to be the most reliable tests for this purpose. ${ }^{23}$ Moreover, SIC has also been reported as the gold standard that can adequately indicate the presence of occupational asthma. The mechanism of this test is to mimic the exposure to irritants to trigger occupational asthma-like symptoms similar to what occurs at the workplace. ${ }^{18}$

PEF monitoring was also reported as a valid measure. However, it has low sensitivity when compared to the aforementioned tests. ${ }^{21,27}$ Molecular diagnosis and immunological workup have recently been introduced in the literature with many favorable outcomes. Assessment of sIgE by SPT can significantly add to the diagnostic approaches of some phenotypes of occupational asthma that are IgE-mediated and can also identify some of the causative agents, including the HMW and LMW compounds. ${ }^{19,28,29}$ Molecular diagnosis can aid in the process of diagnosis. Nevertheless, the main challenge would be to standardize the test to discover the potential allergens. BAT can also be used to discover occupational causative agents, however, many challenges have been reported with these tests as a result of the associated limitations..$^{30-32}$ Testing for biomarkers of inflammation can also be another diagnostic tool that might idnicate the presence of occupational asthma. For instance, previous studies demonstrated that the presence of elevated sputum esonophila was a good predictor for diangosing occupational asthma by LMW and HMW agents. ${ }^{33,34}$
Applying FeNO in this regard is controversial and further validation of the current evidence is still needed. ${ }^{20}$

\section{Treatment}

After the adequate diagnosis of occupational asthma has been established, affected patients should be managed by the same approaches that are applied to non-work-related asthma. Such measures include exposure control to the environmental triggers, asthma education, and the appropriate administration of pharmacological modalities. The latter approach is usually intended to reduce the risk of future events and maximize the benefits of symptoms reduction. Emergency treatment can also be indicated in some cases when the level of exposure is considered excessive. However, it should be noted that applying interventions against exposure to environmental factors would remain the cornerstone in achieving better management regardless of the administered pharmacological modalities.

The management approaches might also differ based on the clinical phenotypes of occupational asthma. Studies indicate that patients with sensitizer-induced asthma should be managed by reallocating them to a different environment. ${ }^{20}$ This has been indicated in a previous Cochrane review which indicated that complete removal of exposure was associated with a significant enhancement in lung functions. ${ }^{35}$ Besides, another meta-analysis reported that partial removal of exposure was not associated with favorable outcomes as compared to complete avoidance of exposure. ${ }^{36}$ However, it should be noted that in cases when the socioeconomic parameters might interfere with reallocation of the affected patients to another workplace to minimized and eliminate the risk of exposure is not feasible, taking preventions to reduce the risk of exposure is reasonable in such cases to minimize the risk. ${ }^{20}$

Studies have previously demonstrated that adequate application of primary, secondary, and tertiary preventions can significantly reduce the severity and prevalence of sensitizer-induced occupational asthma. Previous studies have also indicated the effectiveness of using respiratory protective equipment, ${ }^{37}$ however, these measures should not be considered safe approaches, especially when used on a long-term basis and in patients suffering from severe illnesses. ${ }^{38}$ Figure 1 shows the primary, secondary, and tertiary preventive measures that were reported in the literature. Allergen immunotherapy can also be used as an effective pharmacological therapy that can relieve symptoms and enhance outcomes. ${ }^{39,40}$ On the other hand, patients suffering from irritant-induced occupational asthma can safely continue their work by applying adequate interventions to minimize the risk of exposure and with adequate asthma control. Oxygen supplementation, administration of corticosteroids, and bronchodialtors inhalation can significantly enhance the outcomes in these patients together with rapidly minimizing the exposure to the irritant when asthma symptoms are triggered. ${ }^{19-21}$ 
Job modifications, respiratory protective devices, and engineering controls can significantly enhance the environment and reduce the risk of exposure to irritative compounds, which will subsequently reduce the severity of asthma. ${ }^{41}$ Education of workers and affected personnel, adequate administration of medical treatment, follow-up programs, and proper application of the prevention measures can effectively reduce the risk and severity of this type of occupational asthma and enhance the outcomes of the affected patients. In this context, affected patients can safely return to their work with no need to discontinue it or change the workplace. Nevertheless, they should be followed up regularly and should be educated to apply adequate interventions to reduce the risk of exposure and stick to their medical treatment to enhance the symptoms and obtain better outcomes.

\begin{tabular}{|c|c|}
\hline Prevention & Measures \\
\hline Primary & $\begin{array}{l}\text { - Avoidance of the introduction of new possibles sensitizing agents in the workplace } \\
\text { - Using safe alternatives to sensitizing agents } \\
\text { - } \\
\text { - Eduction of the sensitizing potential of agents by chemical or physical process } \\
\text { - Occupational hygiene measures to reduce exposure to work sensitizers (e.g., use of } \\
\text { robotics, containment, ventilation) }\end{array}$ \\
\hline $\begin{array}{c}\text { Secondary } \\
\text { (early detection) }\end{array}$ & $\begin{array}{l}\text { - Institute medical-surveillance programs for workers at risk (e.g., periodic respiratory } \\
\text { questionnaires, spirometry) } \\
\text { Education of healthcare workers about OA } \\
\text { - Education of workers about the risk of OA and to recognize the symptoms of the } \\
\text { disease (e.g., workplace or public education programs, information by } \\
\text { healthcare provider) }\end{array}$ \\
\hline $\begin{array}{c}\text { Tertiary } \\
\text { (appropiate treatment) }\end{array}$ & $\begin{array}{l}\text { - Evaluation of symptomatic workers to achieve an early and accurate diagnosis } \\
\text { - Workers' relocation to reduce the risk of further exposure once the diagnosis } \\
\text { is confirmed } \\
\text { - Controlling other possible triggers of asthma } \\
\text { - Pharmacological treatment to control asthma } \\
\text { - } \text { the diagnosis } \\
\text { Monitoring of the patient's asthma control in future work environment to ensure } \\
\text { safe placement. }\end{array}$ \\
\hline
\end{tabular}

Figure 1: Primary, secondary, and tertiary interventions for sensitizer-induced occupational asthma. ${ }^{5,20}$

\section{CONCLUSION}

The diagnosis of asthma is based on obtaining a thorough personal and clinical history from the affected patient. However, such approaches have been reported to have low specificity rates, and therefore, the diagnosis should be established by other measures as lung function tests. The management of asthma is hugely dependant on the clinical phenotypes of occupational asthma, however, applying adequate interventions can significantly enhance the outcomes in the affected patients, in addition to the other measures that have been adequately discussed in the manuscript.

Funding: No funding sources

Conflict of interest: None declared

Ethical approval: Not required

\section{REFERENCES}

1. Dykewicz MS. Occupational asthma: current concepts in pathogenesis, diagnosis, and management. J Allergy Clin Immunol. 2009;123(3):519-28.
2. Maestrelli P, Boschetto P, Fabbri LM, Mapp CE. Mechanisms of occupational asthma. J Allergy Clin Immunol. 2009;123(3):531-42.

3. Malo JL, Vandenplas O. Definitions and classification of work-related asthma. Immunol Allergy Clin North Am. 2011;31(4):645-62.

4. Tarlo SM, Balmes J, Balkissoon R, Beach J, Beckett W, Bernstein D, et al. Diagnosis and management of work-related asthma: American College Of Chest Physicians Consensus Statement. Chest. 2008;134(3):1-41.

5. Tarlo SM, Lemiere C. Occupational asthma. N Engl J Med. 2014;370(7):640-9.

6. Malo JL, Yeung M. Agents causing occupational asthma. J Allergy Clin Immunol. 2009;123(3):545-50.

7. Rosenman KD, Beckett WS. Web based listing of agents associated with new onset work-related asthma. Respir Med. 2015;109(5):625-31.

8. Nicholson PJ, Cullinan P, Taylor AJ, Burge PS, Boyle C. Evidence based guidelines for the prevention, identification, and management of occupational asthma. Occup Environ Med. 2005;62(5):290-9. 
9. Donald JC, Keynes HL, Meredith SK. Reported incidence of occupational asthma in the United Kingdom, 1989-97. Occup Environ Med. 2000;57(12):823-9.

10. Piipari R, Keskinen H. Agents causing occupational asthma in Finland in 1986-2002: cow epithelium bypassed by moulds from moisture-damaged buildings. Clin Exp Allergy. 2005;35(12):1632-7.

11. Siracusa A, Marcucci F, Spinozzi F, Marabini A, Pettinari L, Pace ML, et al. Prevalence of occupational allergy due to live fish bait. Clin Exp Allergy. 2003;33(4):507-10.

12. Lindström I, Karvonen H, Suuronen K, Suojalehto H. Occupational asthma from biological pest control in greenhouses. J Allergy Clin Immunol Pract. 2018;6(2):692-4.

13. Cullinan P, Harris JM, Newman TAJ, Hole AM, Jones M, Barnes F, et al. An outbreak of asthma in a modern detergent factory. Lancet. 2000;356(9245):1899-900.

14. Quirce S, Baeza ML, Tornero P, Blasco A, Barranco $\mathrm{R}$, Sastre J. Occupational asthma caused by exposure to cyanoacrylate. Allergy. 2001;56(5):446-9.

15. Jaakkola MS, Leino T, Tammilehto L, Ylöstalo P, Kuosma E, Alanko K. Respiratory effects of exposure to methacrylates among dental assistants. Allergy. 2007;62(6):648-54.

16. Moscato G, Pignatti P, Yacoub MR, Romano C, Spezia S, Perfetti L. Occupational asthma and occupational rhinitis in hairdressers. Chest. 2005;128(5):3590-8.

17. Muñoz X, Cruz MJ, Orriols R, Bravo C, Espuga M, Morell F. Occupational asthma due to persulfate salts: diagnosis and follow-up. Chest. 2003;123(6):2124-9.

18. Trivedi V, Apala DR, Iyer VN. Occupational asthma: diagnostic challenges and management dilemmas. Curr Opin Pulm Med. 2017;23(2):177-83.

19. Vandenplas O, Suojalehto H, Cullinan P. Diagnosing occupational asthma. Clin Exp Allergy. 2017;47(1):6-18.

20. Cormier M, Lemière C. Occupational asthma. Int J Tuberc Lung Dis. 2020;24(1):8-21.

21. Vandenplas O, Dressel H, Nowak D, Jamart J, ERS Task Force on the Management of Work-related Asthma. What is the optimal management option for occupational asthma? Eur Respir Rev. 2012;21(124):97-104.

22. Malo JL, Ghezzo H, Archevêque J, Lagier F, Perrin B, Cartier A. Is the clinical history a satisfactory means of diagnosing occupational asthma? Am Rev Respir Dis. 199;143(3):528-32.

23. Quirce S, Campo P, Ortega J, Nieto M, Gómez E, Arcediano A, et al. New developments in workrelated asthma. Expert Rev Clin Immunol. 2017;13(3):271-81.

24. Bardy JD, Malo JL, Séguin P, Ghezzo H, Desjardins J, Dolovich J, et al. Occupational asthma and IgE sensitization in a pharmaceutical company processing psyllium. Am Rev Respir Dis. 1987;135(5):1033-8.

25. Burge PS. Single and serial measurements of lung function in the diagnosis of occupational asthma. Eur J Respir Dis Suppl. 1982;123:47-59.

26. Malo JL, Cartier A. Occupational asthma in workers of a pharmaceutical company processing spiramycin. Thorax. 1988;43(5):371-7.

27. Malo JL, Côté J, Cartier A, Boulet LP, L'Archevêque J, Yeung M. How many times per day should peak expiratory flow rates be assessed when investigating occupational asthma? Thorax. 1993;48(12):1211-7.

28. Kampen V, Blay F, Folletti I, Kobierski P, Moscato $\mathrm{G}$, Olivieri M, et al. EAACI position paper: skin prick testing in the diagnosis of occupational type I allergies. Allergy. 2013;68(5):580-4.

29. Moscato G, Pala G, Barnig C, Blay F, Giacco SR, Folletti I, et al. EAACI consensus statement for investigation of work-related asthma in nonspecialized centres. Allergy. 2012;67(4):491-501.

30. Vandenplas O, Froidure A, Meurer U, Rihs HP, Rifflart C, Soetaert S, et al. The role of allergen components for the diagnosis of latex-induced occupational asthma. Allergy. 2016;71(6):840-9.

31. Aranda A, Campo P, Palacin A, Doña I, Gomez C, Galindo L, Perales A, et al. Antigenic proteins involved in occupational rhinitis and asthma caused by obeche wood (Triplochiton scleroxylon). PLoS One. 2013;8(1):53926.

32. Raulf M, Quirce S, Vandenplas O. Addressing Molecular Diagnosis of Occupational Allergies. Curr Allergy Asthma Rep. 2018;18(1):6.

33. Quirce S, Sastre J. Occupational asthma: clinical phenotypes, biomarkers, and management. Curr Opin Pulm Med. 2019;25(1):59-63.

34. Vandenplas O, Alpaos V, Heymans J, Jamart J, Thimpont J, Huaux F, et al. Sputum eosinophilia: an early marker of bronchial response to occupational agents. Allergy. 2009;64(5):754-61.

35. Henneberger PK, Patel JR, Groene GJ, Beach J, Tarlo SM, Pal TM, et al. Workplace interventions for treatment of occupational asthma. Cochrane Database Syst Rev. 2019;10(10):6308.

36. Vandenplas O, Dressel H, Wilken D, Jamart J, Heederik D, Maestrelli P, S, et al. Management of occupational asthma: cessation or reduction of exposure? A systematic review of available evidence. Eur Respir J. 2011;38(4):804-11.

37. Baur X, Sigsgaard T, Aasen TB, Burge PS, Heederik $\mathrm{D}$, Henneberger $\mathrm{P}$, et al. Guidelines for the management of work-related asthma. Eur Respir J. 2012;39(3):529-45.

38. Tiotiu AI, Novakova S, Labor M, Emelyanov A, Mihaicuta S, Novakova P, et al. Progress in Occupational Asthma. Int J Environ Res Public Health. 2020;17(12):4553.

39. Moscato G, Pala G, Sastre J. Specific immunotherapy and biological treatments for occupational allergy. Curr Opin Allergy Clin Immunol. 2014;14(6):576-81. 
40. Lavaud F, Bonniaud P, Dalphin JC, Leroyer C, Muller D, Tannous R, et al. Usefulness of omalizumab in ten patients with severe occupational asthma. Allergy. 2013;68(6):813-5.

41. Bernstein DI. Management of the individual worker with occupational asthma. Ann Allergy Asthma Immunol. 2013;111(3):167-9.

Cite this article as: Rahman RS, Ebrahim HRA, Alqahtani JH, Alomani DJ, Al-lihaibi AY, Althaidy MM, et al. Causes, diagnosis and treatment of occupational asthma. Int J Community Med Public Health 2021;8:5545-50. 